\title{
BALANCING WORK AND FAMILY IN \\ CANADA: An EMPIRICAL EXAMINATION OF CONCEPTUALIZATIONS AND MEASUREMENTS
}

\author{
ANNETte TÉZLi \\ AnNe H. GauthieR
}

\begin{abstract}
The issue of work and family balance has been on the agenda of many governmental and nongovernmental organizations in recent years and has led to the adoption of various policies. However, combining work and family responsibilities remains a challenge for many parents. In this paper, we examine the work-family conflict experienced by Canadian working parents. For the purpose of this paper, work-family conflict is conceptualized as the time-related stress arising from the competing demands of the different roles imposed on working parents. Our objective is three-fold. First, we take a critical look at how time stress has been conceptualized and measured in previous studies. Using data from the 2005 Canadian General Social Survey on time use, we suggest an alternative multi-item scale. Second, we examine the impact of different predictors on parents' time stress, paying special attention to the impact of work-related factors. Finally, we discuss the impact of provincial variations in family policy on parents' time stress. Although Québec has introduced a number of familyoriented policies, we do not find evidence that these policies have resulted in less time stress for working parents in Québec.
\end{abstract}

Keywords: work-family conflict, time stress, family, parents, family policy, Québec

Résumé. La balance entre le travail et la famille est un sujet qui a été présent sur l'agenda de plusieurs gouvernements et organisations non-gouvernementales au cours des dernières années et qui a donné lieu à l'adoption de diverses politiques. Cependant, la combinaison des responsabilités reliées au travail et à la famille demeure un défi pour de nombreux parents. Dans ce papier, nous examinons le stress temporel (time stress) vécu par les parents Canadiens qui ont un emploi rémunéré. Notre objectif est triple. Premièrement, nous portons un regard critique sur la façon dont le stress temporel a été conceptualisé et mesuré dans les études antérieures. Sur la base des données de l'enquête canadienne 
générale sur l'emploi du temps de 2005, nous suggérons une échelle multi-items. Deuxièmement, nous examinons l'impact de différentes variables sur le stress temporel des parents tout en portant une attention toute spéciale sur les variables reliées au travail. Finalement, nous discutons de l'impact des variations provinciales en matière de politique familiale sur le stress temporel des parents. Bien que le Québec ait introduit un nombre de politiques reliées à la famille, nous n'obtenons pas de résultats qui suggèrent que ces politiques ont réduit le stress temporel pour les parents québécois qui ont un emploi.

Mots clés: le stress temporel; la famille; les parents; politique familiale; Québec

\section{INTRODUCTION}

ver the past decades, Canada, like other postindustrial societies, has undergone a number of demographic, social, and economic changes which have significantly altered the conditions of contemporary family life (Duxbury et al. 2003; Lapierre-Adamcyk et al. 2006). These changes have contributed to the erosion of traditional gender roles, encouraged women to join the labour force, and gradually led to changes in the gendered division of domestic labour (Edwards and Rothbard 2005). In addition, due to the stagnating earnings of men and rising costs of living, an increasing number of families have come to depend on a second income to secure economic resources, gradually making dual-earner families the norm (Gornick and Meyers 2003; Jacobs and Gerson 2004; Ravanera and McQuillan 2006).

Over the past decades, men's labour force participation rates declined slightly, while women's labour force participation increased significantly, approaching that of men (Luffman 2006). In 1976, a little less than half (46\%) of all women age 25-54 participated in the labour force (Statistics Canada 2006), compared to $80.9 \%$ in 2006 (Statistics Canada 2008). Although women with children are still less likely to work for pay than women without children, mothers' increased labour force participation, especially among women with very young children, contributed significantly to the overall rise in the women's labour force participation rate. In 1976, 39\% of women with children worked outside the home, compared to $73 \%$ in 2004, the majority of whom work full-time (Statistics Canada 2006).

While women's labour force participation approaches that of men, women continue to spend more time on unpaid domestic labour than men, suggesting that changes in the private sphere have not kept pace with changes outside the home (Beaujot and Andersen 2007; Doucet 1995). Instead, societal values, norms, and ideologies tend to perpetu- 
ate the male breadwinner-image and the role of women as caretakers and domestic workers (Doucet 2000; Hays 1996; Ranson 1999). As the detailed accounts of Duxbury and colleagues (2003) and Hays (1996) suggest, many women, but particularly mothers, feel the strain induced by managing the dual responsibility for paid work outside and unpaid work inside the home, often leaving women feeling inadequate and as a failure in both domains.

At the same time as an increasing number of women were entering the labour force, economic changes affected working conditions and demands such as longer or nonstandard work hours (Beaujot and Andersen 2007; Lapierre-Adamcyk et al. 2006). Contemporary workplace cultures and their impact on the organization of work are built predominantly on the male breadwinner family model. This model presupposes that workers, whether male or female, have minimal family involvement and demands continuous, full-time dedication to paid employment (Gornick and Meyers 2003; Jacobs and Gerson 2004). For example, women in professional jobs, who, due to childcare and other domestic responsibilities, are not able to meet those demands are often condemned to pursue the "mommy track," which better accommodates family responsibilities but precludes career advancements (Duxbury et al. 2003; Hays 1996).

Since women continue to bear primary responsibility for childcare and unpaid domestic labour, they tend to reduce time spent in paid employment when paid and unpaid work become irreconcilable (Jacobs and Gerson 2004). In addition, many women continue to work part time, take on temporary employment, or are self-employed to accommodate their childcare responsibilities (Cooke-Reynolds and Zukewich 2004; Statistics Canada 2006). However, those forms of nonstandard employment are precarious as they tend to be less well paid, provide women with only limited career opportunities, are insecure, and often do not provide benefits (Cooke-Reynolds and Zukewich 2004). Thus, while women's labour force participation continues to increase, many working parents, especially mothers, experience difficulties in consolidating work and family responsibilities: a situation which creates new and multifaceted challenges for the daily lives of contemporary Canadian families (Ravanera and McQuillan 2006).

In light of the time constraints and resulting tensions that many dualpartner working families experience in their daily efforts to juggle paid and unpaid domestic work, the issue of work-family conflict has generated much public, scientific, and political debate (MacDermid 2005). Yet, the conflict between work demands and family needs has been met with insufficient institutional support or family-friendly policies, either at the employer or the governmental level (Jacobs and Gerson 2004). 
Furthermore, the root causes of the work-family time squeeze, its consequences, and means of alleviating the stress, have been the subject of little empirical research in Canada (Duxbury et al. 2003). In this paper, we contribute to the literature in three ways. First, we take a critical look at how time stress has been conceptualized and measured in previous studies and suggest an alternative multi-item scale. Second, we examine the impact of different predictors on parents' time stress, paying special attention to the impact of work-related factors. Finally, we discuss the impact of provincial variations in family policy on parents' time stress.

\section{Work-Family Conflict}

The conflict between work and family spheres is commonly conceptualized using role conflict and role strain approaches (Friede and Ryan 2005; Kossek and Lambert 2005). Combining these approaches, Greenhaus and Beutell (1985) point to three types of conflict emerging from the competing demands of the work and the family domains. First, timerelated conflicts between the work and family spheres arise when time strain in one domain spills over into the other domain. Second, working parents face strain-based conflicts when tensions arising in one field affect their role performance in the other field. Finally, an individual's parental role performance may be impeded by certain behaviours that are required in the work sphere or vice versa, which can result in behaviourbased strain. These three types of conflicts can result in time constraints which in turn might lead to stress experienced by working parents. ${ }^{1}$ Thus, the work-family conflict is commonly operationalized through time and stress related measurements (Friede and Ryan 2005).

Since time is a finite resource that cannot be expanded in periods of scarcity, individuals who occupy multiple roles have to make decisions in allocating time (Jacobs and Gerson 2004). Research shows that many working parents face difficulties finding affordable, good quality as well as continuous childcare arrangements; are working longer hours than previous generations; and often have to take work home (Duxbury and

1. In light of the many existing definitions and conceptualizations of stress, we do not explicitly define stress for the purpose of our paper. Furthermore, Statistics Canada did not provide research participants with a definition of stress but rather, when answering stress-related questions, research participants employed their own understanding of stress. Loosely defined, stress is a problematic physical and/or emotional response to strain, where strain is defined as an individual's negative balance between resources, abilities, and needs versus external requirements and demands (Park 2007). We further refrain from a detailed discussion of cause-effect relationships between strain and stress, as this is not the focus of our paper and has been done in detail elsewhere (see, for example, Cohen and Wills 1985; Hobfoll and Spielberger 2003; Walker 1985). 
Higgins 1994). At the same time, despite an increase in the number of women entering the labour force and a general expansion of hours spent in paid employment, parents have not responded to the ensuing strain on their time by reducing the time spent with their children (Beaujot and Andersen 2007; Gauthier et al. 2004; Zuzanek 2000). Hence, working parents find themselves in a double bind; work demands and family responsibilities compete for time allotment. This struggle can be a significant source of stress (Duxbury et al. 1999; Jacobs and Gerson 2004; Zukewich 2003). Stress, in turn, has a number of negative consequences including repercussions for the individual, the family, the child(ren), the workplace, and society at large (Duxbury et al. 2003; Gornick and Meyers 2003; Zuzanek 2000). Stress negatively impacts well-being by impairing an individual's mental and physical health, and by causing marital conflict, tensions within the family, impaired parenting behaviour, as well as dissatisfaction with family life in general (Frederick and Fast 2001; Zukewich 2003).

In addition, the conflict between the public and the private domains affects parents in their capacity as workers. Women missed an average of ten days of work for family related reasons in 2004 (Statistics Canada 2006). In comparison, men missed an average of two days in 2004 (Statistics Canada 2006), which indicates that in case of a family emergency, women tend to take time off in order to cater to their family's needs. Moreover, women occasionally arrive at work late or have to leave their workplace early because of a problem with their childcare arrangements or family emergencies (Hofferth et al. 1991). Putting the family first in case of an emergency negatively affects their status in an organizational culture that awards dedication to, and extensive time investment in, one's paid work (Duxbury et al. 1999; Hays 1996). Furthermore, stress related to the competing demands of work and family responsibilities can distract workers, affect their concentration, cause burnout syndromes, and lower job satisfaction. Stress also may decrease organizational commitment, which can affect workers' productivity, lead to absenteeism, and result in high turnover rates (Duxbury et al. 1999; Frederick and Fast 2001; Glass and Estes 1997). Lowered productivity and effectiveness have negative effects on individuals and their families by jeopardizing their occupational and financial attainment (Glass and Estes 1997). At the same time, high turnover rates and low employee productivity negatively affects organizations (Duxbury et al. 1999).

Finally, parental employment and related stress can curtail parents' ability to fully engage in their children's lives, which may negatively affect child development and child well-being (Cook and Willms 2002; Gornick and Meyers 2003). In addition to entering the labour force, 
women are the primary provider of childcare and responsible for the majority of the unpaid domestic labour. Working mothers are further pressured by sometimes contradictory cultural imperatives that identify the mother as the primary caregiver, demand intensive mothering as well as full dedication to one's job, and sustain the notion working mothers cannot adequately cater to the needs of their children (Hays 1996; Jacobs and Gerson 2004). Thus, working mothers feel more strain to balance the responsibilities of paid and unpaid labour than working fathers do (Duxbury and Higgins 1994). Understanding the determinants of the work-family conflict is therefore very important. In what follows, we review the empirical findings by first focusing on individual, family, and work predictors, and then by suggesting contextual factors that should be included in the empirical examination of work-family conflict. ${ }^{2}$

\section{Individual, Family, and Work Characteristics}

According to data from the Organization for Economic Cooperation and Development (OECD), 76\% of Canadian women participated in the labour force in 2005 (OECD 2005). Women also bear primary responsibility for childcare and domestic work and thus report higher levels of time strain and stress than men (Benoît-Paul and Grey 2006; Gornick and Meyers 2003; Zuzanek 2000). In addition, Beaujot and Andersen (2007) found that the impact of different factors on stress levels vary by gender. Family-related factors have a greater impact on women, while work-related factors have a stronger effect on men. Age is another characteristic that has been linked to differences in time strain. Benoît-Paul and Grey (2006) found that time-crunch, or being pressed for time, is most pronounced during the early thirties and then begins to decline. Similarly, Fast and Frederick (2004) and Zukewich (2003) showed that various life events such as marriage, employment, child rearing, or retirement exert different time strain on individuals across the life course.

Over time, the number of individuals reporting high levels of time strain has risen in the entire Canadian population but the increase was particularly pronounced among parents (Zuzanek 2000). Parents, particularly mothers, face greater time strain and related stress than individuals who do not have children (Beaujot and Andersen 2007; Bellavia and Frone 2005; Zukewich 2003). However, variations in parents' stress lev-

2. While a number of studies on this topic have been conducted in the US and Europe, the different policy contexts are assumed to produce different frameworks in which families operate. For that reason, the review presented here focuses mainly on the Canadian literature. In our discussion of contextual factors of work-family conflict, however, we consult the European literature as the European body of research provides extensive discussions of the relevance of policy contexts in comparative perspective. 
els appear to be mainly related to the age, rather than the number, of children living in the household (Benoît-Paul and Grey 2006). Furthermore, while young children in the household increase levels of time strain, the magnitude of the pressures declines as children get older (Benoît-Paul and Grey 2006; Duxbury et al. 2003; Zuzanek 2000).

Work-related predictors are among the most important factors contributing to time-crunch and stress, particularly hours spent in paid employment (Beaujot and Andersen 2007; Bellavia and Frone 2005). Today's 24/7 economy requires production and productivity around the clock and thus mandates shift work, which often interferes with family responsibilities of individuals employed in sectors relying heavily on shift work (Presser 2004; Williams 2008). Other work-related factors such as working from home, working nonstandard hours (standard hours are defined as Monday-Friday, 9 am to $5 \mathrm{pm}$ ), holding multiple jobs, or having a flexible work schedule (defined as being able to choose beginning and end time of one's work day) produced ambiguous results. Benoit-Paul and Grey (2006) found that respondents with a flexible work schedule were less time crunched. On the other hand, working shifts, being self-employed, or working irregular hours did not significantly affect individuals' perception of time pressure. Similarly, MacDonald et al. (2005) showed that once work hours were controlled for, specific work characteristics such as having a flexible schedule, working in multiple jobs, or working irregular shifts had a limited effect, if any, on individuals' stress levels and satisfaction with work-family balance.

Zuzanek (2000), on the other hand, showed that shift work, particularly working night shifts, is correlated with increased levels of time pressure and lower levels of satisfaction with the balance between work and home life. Differences in research findings can in part be attributed to the vast differences in the types of shift work. Some shift workers work rather regular shifts, which allows establishing daily routines. Others, however, work rotating or split shifts, are on call, or work constantly changing shift schedules, including nights, weekends, or holidays, which makes scheduling family activities difficult (Williams 2008).

According to Jacobs and Gerson (2001), women's entry into the labour force led to an increase in the combined working time of couples. Thus, time formerly available for domestic labour is curtailed by the amount of time that couples spend in paid employment. A partner or spouse's contributions to domestic labour and childcare might alleviate some of an individual's time pressures and thus subsequent stress. Conversely, when partners or spouses work long hours or contribute little to the unpaid work in the home, the lack of support can add additional bu- 
rden to the already time-crunched individual (Frederick and Fast 2001; MacDonald et al. 2005).

\section{Contextual Factors}

Working parents are not only caregivers and earners but also members of their local community as well as the larger society. Embedded in a country's economic and political system, family life is shaped by the economic and social conditions families encounter (Ravanera and McQuillan 2006). To alleviate the causes and consequence of this stress, some authors have emphasized the importance of family-friendly policies, both at the organizational and the national level (Cook and Willms 2002; Jacobs and Gerson 2004; Saltzstein et al. 2001). Family policies affect family life by structuring the context in which families operate and make decisions and defining opportunity and constraint matrices as well as parental rights and responsibilities (Gauthier 2007).

There are considerable variations in countries' efforts to implement family-friendly policies that aid working parents in reconciling work and family responsibilities (OECD 2005; Strandh and Nordenmark 2006). Based on existing research, Strandh and Nordenmark (2006) hypothesized that the differences in family-friendly policies across European countries should result in variations in the ability of employed parents to integrate paid and unpaid labour. Different policies should result in differences in the ways parents experience the conflict between their work and family responsibilities.

While some studies examine the effects of family-friendly policies in the workplace on perceptions of work-family balance and conflict (see, for example, Saltzstein et al. 2001), studies that systematically examine the effect of family-friendly policies across policy contexts in North America are hard to come by (for a notable exception see, for example, Roy and Bernier 2007). Canada lends itself naturally to such an analysis as provinces vary greatly in their implementation of family-friendly policies. The individual responsibility model, which ascribes sole responsibility for a family's economic well-being as well as the provision of care for its members to the parents, dominates most Canadian provinces' family policy development (Cheal et al. 1998). In contrast, Québec's recent family policies bear traces of the Scandinavian model, assuming public responsibility for families' well-being (Girard 1994; O'Hara 1998). In the words of Le Bourdais and colleagues (1994:103): "Quebec is without a doubt the only Canadian province in which family policy is governed by a complete set of coherent measures aimed specifically at the well-being of families." Thus, only Québec has implemented family- 
friendly policies over the past decade, directly supporting working families in the combination of parental and employment responsibilities (O'Hara 1998; OECD 2005; Roy and Bernier 2007).

Québec offers a variety of financial benefits to parents including a family allowance which supplements the Canada Child Tax Benefit (National Child Benefit Supplement), Child Assistance, the Universal Childcare Benefit, a series of tax credits, and a Parental Insurance Plan providing additional financial security during maternity or parental leave, helping parents with the expenses of raising children. ${ }^{3}$ In addition, employees in Québec have the right to take up to 10 days of leave should family obligations require their absence from work. Finally, the provincial family policy package focuses on the provision of quality childcare, emphasizing the availability of childcare as well as the necessity of concerted child development in such settings. While other provinces offer subsidized childcare only to low-income families, the province of Québec enacted policies that provide low and middle income parents with childcare at a cost of $\$ 7$ per day (Jenson and Thompson 1999).

Previous research indicates that individual behaviour and perceptions are influenced by the policy context in which the individual is embedded. A policy context that is supportive of the integration of parents' paid and unpaid labour should alleviate parents' perception of work-family conflict, compared to a policy context that does not facilitate parents' paid and unpaid work (Strandh and Nordenmark 2006). The supportive family policies enacted by the province of Québec can be expected to facilitate the combination of parents' paid and unpaid work and thereby alleviate parents' perceived work-family conflict. Since Québec is unique in Canada, in supporting working parents to combine paid and unpaid work, working parents in Québec should have lower levels of work-family conflict than working parents in other Canadian provinces.

\section{Research Objectives}

For our purposes, the work-family conflict is understood as the timerelated stress arising from the competing demands that working parents must take on. This operationalization is commonly used in the Canadian context (see, for example, Beaujot and Andersen 2007; BenoîtPaul and Grey 2006; Frederick and Fast 2001; MacDonald et al. 2005; Zukewich 2003). We use data from the Canadian 2005 General Social

3. For a detailed overview of benefits, benefit levels, and eligibility criteria see $\underline{\mathrm{http}: / /}$ www.mfa.gouv.qc.ca/services-en-ligne/guide-programmes-services/table.asp?lang=en (access date: 04, 2008).

4. This operationalization is problematic (see, for example, MacDermid 2005) because it presupposes that demographic changes inevitably lead to role conflict and strain. 
Survey (GSS) Time Use in this paper. ${ }^{5}$ Our objective is threefold. First, in previous studies which employed the Canadian GSS Time Use data set, the work-family conflict was measured predominantly by using a time-crunch scale, single-item stress indicators, or a single-item indicator measuring respondents' satisfaction with the balance between their work and home life. We will take a critical look at those indicators and compare them to an alternative multi-item scale we developed for this paper. Second, we examine the impact of family and work characteristics on parents' time stress, paying special attention to the impact of working hours and conditions of work. Finally, we discuss the impact of provincial variations in family friendly policies on parents' perception of time stress.

\section{Data, Variables and Method}

In the 2005 Canadian General Social Survey (GSS) Time Use cycle, computer assisted telephone interviewing (CATI) was used to collect data on 19,597 persons age 15 and older, living in private households in the 10 Canadian provinces. The response rate for this survey was $58.6 \%$. We restricted our sample to employed individuals who lived with at least one dependent child under the age of 15 . In addition, we restricted our analysis to two-parent families ${ }^{6}$ (see also Lapierre-Adamcyk et al. 2006) and to respondents between the ages of $25-54 .{ }^{7}$ This limited the number of cases available for analysis to 2,417 respondents. All analyses have been conducted with person-weighted data.

\section{Dependent Variables}

In other studies based on earlier cycles of the Canadian time use survey, three main measures of work-family conflict were used: a multiitem time-crunch scale, a single-item stress variable, and a single-item

5. While the 2006 GSS cycle 20 on family transition includes a variety of measures that would allow us take into consideration current theoretical developments, the data set had not been released at the time of our analysis.

6. We chose to focus on two-parent families for two main reasons. First, we would argue, single parents face a somewhat different opportunity and constraint structure than twoparent families, which would add a comparative component to our analysis that was beyond the scope of this paper. Second, in accordance with the existing literature, we were interested in controlling for a number of the respondents' partner/spouse characteristics, which required excluding single-parent families from the analysis.

7. According to Statistics Canada, the average age of Canadian women giving birth for the first time was 28 years in 2003 (Statistics Canada 2005). In addition, men and women between the age of 25-54 are most likely to participate in the labour force. Thus, between the ages of 25-54 both men and women are most likely to be employed and have children to care for (Cooke-Reynolds and Zukewich 2004). 
work-family balance variable (see, for example, Beaujot and Andersen 2007; Benoît-Paul and Grey 2006; Frederick and Fast 2001; Zukewich 2003). We retained these three measures to allow comparison with earlier studies. However, because of the limitations of these measures, we also developed an alternative multi-item time-related stress scale, ${ }^{8}$ which is based on six questions contained in the 2005 GSS.

First, respondents were asked: "How often do you feel rushed?" The six answer categories ranged from "every day" (1) to "never" (6) and had to be reverse-coded in order to follow the logical order of the other five variables. The second question we included was: "Do you feel the days are just too short to do all the things you want?" which respondents could answer with "yes" (1) or "no" (0). Third, the question "At the end of the day, do you feel that you have not accomplished what you set out to do?" was included, another dichotomous item. Fourth, "Do you feel constantly under stress trying to accomplish more than you can handle?" was measured with two answer categories: "yes" (1) and "no" (0). The fifth question we used was: "How stressful are most of your days?" The five answer categories ranged from "not at all stressful" (1) to "extremely stressful" (5). Finally, we included "Do you often feel under stress when you don't have enough time?" which respondents could answer with either "yes" (1) or "no" (0). The selection of items is consistent with existing research demonstrating the interconnectedness of time pressures and stress (see, for example, Zukewich 2003).

Since the level of measurement varied across the six items, the scores for all variables were standardized for comparison. ${ }^{9}$ The additional benefit of using standardized values is a continuous scale which allows the use of Ordinary Least Squares (OLS) regression, making ad hoc decisions about cut off values for dichotomization superfluous.

In order to confirm that these six items indeed capture the same underlying conceptual dimension, a confirmatory factor analysis was conducted using the common factor method. The unrotated solution produced one factor with an Eigenvalue larger than 1 (1.736), accounting for $83.7 \%$ of the observed variance. Subsequent examinations using the Piazza method ${ }^{10}$ and the one-factor test based on a maximum likelihood

8. One single indicator insufficiently captures complex concepts such as work-family conflict or time-related stress, particularly when the single indicator is dichotomous or dichotomized. A multi-item indicator tends to account for a larger share of the observed variance in the dependent variable than the single items it is composed of. Thus, multiitem indicators tend to be more reliable and stronger in explanatory power (see, for example, Granato et al. 1996). For a detailed discussion of the benefits of multi-item indicators compared to single-item indicators see Piazza (1980).

9. The six variable scores were standardized by creating values for each item that have a standard deviation of 1 .

10. For a detailed discussion of this method see Piazza (1980). 
factor analysis confirmed that one factor adequately represents the structure underlying those six items. The derived scale includes all six items and the Cronbach alpha of .693 confirms that the proposed set of variables adequately measures the stress construct. Table 1 summarizes the results of the factor analysis.

Table 1: Results Factor Analysis for the Stress Scale, Rotated Solution

\begin{tabular}{|l|c|}
\hline \multicolumn{1}{|c|}{ Time-stress scale } & Factor loading \\
\hline How often do you feel rushed? & .4720 \\
\hline $\begin{array}{l}\text { Do you feel the days are just too short to do all the things } \\
\text { you want? }\end{array}$ & .4116 \\
\hline $\begin{array}{l}\text { At the end of the day, do you feel that you have not } \\
\text { accomplished what you set out to do? }\end{array}$ & .4381 \\
\hline $\begin{array}{l}\text { Do you feel constantly under stress trying to accomplish } \\
\text { more than you can handle? }\end{array}$ & .6612 \\
\hline How stressful are most of your days? & .5749 \\
\hline $\begin{array}{l}\text { Do you often feel under stress when you don't have } \\
\text { enough time? }\end{array}$ & .5689 \\
\hline Eigenvalue & 1.7365 \\
\hline Variance explained by factor & .8371 \\
\hline Cronbach's alpha & .6930 \\
\hline
\end{tabular}

The commonly used time-crunch scale is a multi-item indicator combining the following ten dichotomous (yes/no) items: Do you plan to slow down in the coming year? Do you consider yourself a workaholic? When you need more time, do you tend to cut back on your sleep? At the end of the day, do you often feel that you have not accomplished what you set out to do? Do you worry that you don't spend enough time with your family or friends? Do you feel that you're constantly under stress trying to accomplish more than you can handle? Do you feel trapped in a daily routine? Do you feel that you just don't have time for fun any more? Do you often feel under stress when you don't have enough time? Would you like to spend more time alone?

Previous studies argued in favour of this time-crunch scale, mostly by referring to a high Cronbach's alpha value and high correlations with other stress-related variables (see, for example, Beaujot and Andersen 2007; Zukewich 2003). However, based on our factor analysis we have reservations about the time-crunch scale. While the Cronbach's alpha value is impressive, there seems to be a lack of internal logic and consistency of the scale. Our factor analysis supported this notion by identifying four items that did not load on the same factor as the remaining 
six (results not shown here). ${ }^{11}$ We nonetheless included this time-crunch scale as a link with previous studies and to compare the different conceptualizations of the work-family conflict. We dichotomized the timecrunch scale according to convention, defining those who answer "yes" to seven out of the ten questions as time-crunched (taking on the value of 1) and all others as not time-crunched (taking on the value of 0) (see, for example, Beaujot and Andersen 2007). In our sample, more than a quarter $(28.5 \%)$ of the respondents answered seven out of the ten questions with yes, indicating they are time-crunched.

We also included a single-item measure of stress used by MacDonald et al. (2005) in their analysis of the effect of paid and unpaid work on stress: "Do you feel that you're constantly under stress trying to accomplish more than you can handle?" This was included in our multi-item time stress scale. The original dichotomous variable was recoded as 1 if the respondent answered "yes" and 0 otherwise. In our sample, almost half of all respondents (47\%) stated that they are constantly under stress trying to accomplish more than they can handle.

Finally, the GSS Time Use cycle includes one item speaking directly to the respondents' satisfaction with the balance between job and home life that has been used in previous analyses of the work-family conflict (Frederick and Fast 2001; MacDonald et al. 2005; Zuzanek 2000). ${ }^{12}$ Unfortunately, this item is measured on a nominal scale, which severely curtails its explanatory power. However, we included it as a secondary dependent variable to assess this alternative conceptualization of the work-family conflict focusing on dissatisfaction with work-family balance rather than time pressures and stress emerging from occupying multiple roles. The original variable was recoded as 1 for respondents who are dissatisfied with the balance between work and home life and 0 when respondents were satisfied with the balance. "No opinion" was declared a missing value, which excluded 36 cases. In our sample, about one-third (29\%) of employed parents were dissatisfied with the balance between work and home life. Selected sample statistics for all dependent variables are summarized in Table 2 .

11. The following items had very low $(<.4)$ and negative factor loadings, indicating that they do not capture the same conceptual dimension as the remaining six items and thus should not be included in the time-crunch scale: Do you plan to slow down in the coming year? Do you consider yourself a workaholic? When you need more time, do you tend to cut back on your sleep? Would you like to spend more time alone?

12. Respondents were asked: "Are you satisfied or dissatisfied with the balance between your job and home life?" Answer categories included "satisfied" or "dissatisfied." In addition to the limited explanatory power of dichotomous single-item indicators, Grywacz and Carlson (2007) argued that the question as posed focuses too much on the individual by stressing the psychological notion of satisfaction with such balance rather than its accomplishment. 
Table 2: Sample Characteristics of the Dependent Variables

\begin{tabular}{|l|c|l|c|}
\hline \multicolumn{1}{|c|}{ Variable } & $N$ & Mean & $\begin{array}{c}\text { Standard } \\
\text { Deviation }\end{array}$ \\
\hline Time-stress scale (high scores = stressed) & 2384 & .0106 & 3.7655 \\
\hline Time-crunch scale & 2417 & .2851 & 0.4515 \\
\hline $\begin{array}{l}\text { Do you feel that you're constantly under } \\
\text { stress trying to accomplish more than you can } \\
\text { handle? }\end{array}$ & 2412 & .4731 & 0.4994 \\
\hline $\begin{array}{l}\text { Are you satisfied or dissatisfied with the } \\
\text { balance between your job and home life? }\end{array}$ & 2364 & .2936 & 0.4555 \\
\hline
\end{tabular}

\section{Independent Variables}

The existing literature suggests that the presence of children in the household increases the levels of time pressure and stress levels for the adults in the household. We included the number of children living in the household in a series of dummy variables: living with one child (as the reference category), living with two children, and living with three or more children. In addition, the presence of young children in the household is assumed to exert a certain amount of pressure and stress because the ability for both parents to pursue paid employment depends on the availability of childcare. We created a dummy indicator based on the age of the youngest child in the household variable, coded as 1 when respondents have a child under the age of six living in the household and 0 otherwise.

As previous research has shown, work-related factors are central to the prediction of time-related stress among working parents. We included the number of hours spent at work as a series of dummy variables (1-29, 30-39, 40-49, 50-59, and 60 or more work hours per week) to account for the nonlinear relationship between work hours and our dependent variables. Since working parents have less time available for family responsibilities, as the number of hours in paid employment increase, we expect higher levels of time pressure and stress levels and lower satisfaction with the balance between home and family life. We included working from home, holding multiple jobs, and having schedule flexibility (three dichotomous variables, which were recoded as 1 when the respondent answered "yes" and 0 otherwise). Finally, previous research indicated that working nonstandard hours increases stress and decreases individuals' satisfaction with the balance between work and home life. We dichotomized the original variable and defined anyone not working a regular daytime employment or shift as working nonstandard hours (coded as 1). 
In addition to child and parent characteristics, we included spouse or partner characteristics, which have been shown to either aggravate or alleviate individuals' stress. We operationalized spousal employment by creating three dummy variables: one for a partner or spouse not in the labour force (our reference category), one for part-time employed spouses or partners (working less than 35 hours a week), and one for full-time employed spouses or partners (working 35 hours or more per week). In addition, we calculated the ratio between respondents' and their partner/spouse's time dedication to childcare, distinguishing between equally shared childcare, a partner/spouse who spends less time on childcare than the respondent, and a partner/spouse who spends more time. ${ }^{13}$

Support to parents from outside the home can also buffer the effects of stress. For instance, smaller towns and rural areas may nourish a closely knit community and provide important support networks. Thus, we created a control for region of residence using a dichotomous variable for rural areas or small towns (1) and larger urban centres (0). In addition, we use sense of belonging to the local community as an indicator of connectedness. Respondents who are very or somewhat strongly connected were defined as connected (1) and respondents with a somewhat or very weak sense of belonging were defined as having a weak sense of belonging (0). "No opinion" was defined as a missing value, which eliminated 17 cases.

Finally, following previous research, we used province of residence as a proxy for different policy contexts in Canada (see, for example, Strandh and Nordenmark 2006). To examine the effect of different policy contexts on the stress levels of working parents, we created a series of dummy variables representing the different Canadian provinces. To adjust for the varying population size across provinces, some provinces were combined into regions: Saskatchewan and Manitoba were combined; Newfoundland, Labrador, Prince Edward Island, Nova Scotia, and New Brunswick were combined into the Atlantic region. Québec was left out of the analysis to compare the stress levels of working parents in other provinces to those measured in Québec. Based on the hypothesis put forward by Strandh and Nordenmark (2006), we would expect working parents in Québec to feel less stress in their efforts to combine paid and unpaid work than working parents in other provinces.

Our model also includes a number of demographic variables including gender, age, education, and income. Gender was recoded into

13. For a better conceptualization of the division of domestic labour see Beaujot and Andersen (2007). We did not follow their classification since the impact of the division of domestic labour was not our primary analytic focus. 
a dummy variable, females (1) and males (0). The original grouped age variable was recoded into three age groups: $25-34,35-44$, and 45 years of age and older. ${ }^{14}$ The education variable was recoded into three categories: low education (individuals with a high school diploma or less), medium education (individuals who had some college or university education, vocational training, or a trade certificate), and high education (individuals with postsecondary undergraduate or graduate degrees from any institution of higher education). Finally, we also included a series of dummy variables to capture household income: less than $\$ 20,000 ; \$ 20,000-\$ 39,000 ; \$ 40,000-\$ 59,000 ; \$ 60,000-\$ 79,000$; $\$ 80,000-\$ 99,000$; and $\$ 100,000$ or more. Key sample statistics for all included independent variables are summarized in Table $3 .^{15}$

\section{Results}

The first objective of our analysis was to compare the effects of our independent variable on the three dependent variables utilized in existing studies across different operationalizations of the work-family conflict and compare them to the effects on our proposed standardized stress scale. We ran four models: an OLS regression to examine the effects of all independent variables on our proposed time-stress scale, and three logistic regressions on the dichotomized time-crunch scale, the singleitem stress indicator, and dissatisfaction with the balance between work and home life. The regression results for all four models are summarized in Table 4, reporting standardized and unstandardized regression coefficients for the OLS regression and odds ratios for the three logistic regressions.

A number of variables have a significant effect on the work-family conflict, regardless of how such conflict is conceptualized and operationalized, including gender, a high number of work hours, and a strong sense of belonging to the local community. Across models, women are more likely than men to feel the effects of combining paid and unpaid work. On average, women score more than one point (unstandardized regression coefficient $(b)=1.38)$ higher on the standardized stressed scale than men, controlling for all other variables, which indicates that they experi-

14. The original variable contained 15 age groups in 5-year intervals, 9 of which were not included due to our sample restrictions (individuals younger than 25 and older than 54 years of age).

15. It is important to keep in mind that, on occasion, our sample characteristics might deviate from population characteristics due to the restrictions we imposed on our sample. For example, by excluding the young and individuals older than 54, individuals with high levels of education are overrepresented, while individuals with low levels of education are underrepresented. 
Table 3: Sample characteristics of the independent variables

\begin{tabular}{|c|c|c|c|}
\hline Variable & $N$ & Mean & $S D$ \\
\hline Sex (female) & 2417 & .4187 & .4934 \\
\hline Age groups & 2417 & & \\
\hline 25 to 34 (left out) & & .2507 & .4335 \\
\hline 35 to 44 & & .5606 & .4964 \\
\hline 45 and older & & .1887 & .3913 \\
\hline Education & 2412 & & \\
\hline low (high school diploma or less) (left out) & & .2172 & .4125 \\
\hline med (some college/university, trade) & & .2629 & .4403 \\
\hline high (post-secondary graduate) & & .5199 & .4997 \\
\hline Children under 15 living in the household & 2417 & & \\
\hline 1 (left out) & & .4175 & .4932 \\
\hline 2 & & .4332 & .4956 \\
\hline 3 or more & & .1494 & .3565 \\
\hline Child under 6 in the household & 2417 & .4481 & .4974 \\
\hline Number of work hours & 2417 & & \\
\hline 1 to 29 & & .0939 & .2918 \\
\hline 30 to 39 (left out) & & .4584 & .4984 \\
\hline 40 to 49 & & .2536 & .4352 \\
\hline 50 to 59 & & .1121 & .3706 \\
\hline 60 and more & & .0819 & .2743 \\
\hline Works from home & 2406 & .2070 & .4052 \\
\hline Works multiple jobs & 2407 & .0640 & .2448 \\
\hline Has schedule flexibility & 2406 & .4057 & .4911 \\
\hline Works nonstandard hours & 2406 & .2406 & .4276 \\
\hline Partner/spouse's employment & 2386 & & \\
\hline not employed (left out) & & .3068 & .4613 \\
\hline part time & & .1085 & .3111 \\
\hline full time & & .5847 & .4929 \\
\hline Division of labour on childcare & 2417 & & \\
\hline equal (left out) & & .1477 & .3549 \\
\hline partner/spouse does less & & .3790 & .4852 \\
\hline partner/spouse does more & & .3968 & .4893 \\
\hline Combined household income & 2088 & & \\
\hline$<\$ 20,000$ (left out) & & .0187 & .1354 \\
\hline$\$ 20,000-\$ 39,000$ & & .1025 & .3034 \\
\hline$\$ 40,000-\$ 59,000$ & & .2126 & .4093 \\
\hline$\$ 60,000-\$ 79,000$ & & .2112 & .4083 \\
\hline$\$ 80,000-\$ 99,000$ & & .1729 & .3782 \\
\hline$\$ 100,000$ and more & & .2821 & .4501 \\
\hline Living in a rural area & 2417 & .2445 & .4299 \\
\hline Sense of belonging to the local community & 2389 & .6949 & .4606 \\
\hline Province & 2417 & & \\
\hline Québec (left out) & & .1895 & .3920 \\
\hline Atlantic & & .1949 & .3962 \\
\hline Ontario & & .3029 & .4596 \\
\hline Saskatchewan and Manitoba & & .1096 & .3125 \\
\hline Alberta & & .1023 & .3030 \\
\hline British Columbia & & .1010 & .3013 \\
\hline
\end{tabular}


Table 4: Regression results for all dependent variables

\begin{tabular}{|c|c|c|c|c|c|}
\hline \multirow[t]{2}{*}{$\begin{array}{l}\text { Independent } \\
\text { variables }\end{array}$} & \multicolumn{2}{|c|}{\begin{tabular}{|c|} 
Standardized \\
Stress Scale \\
(OLS regression) \\
\end{tabular}} & \multirow[t]{2}{*}{\begin{tabular}{|c|} 
Time- \\
crunch scale \\
(odds ratios) \\
\end{tabular}} & \multirow[t]{2}{*}{\begin{tabular}{|c} 
Stress \\
item $^{1}($ odds \\
ratios $)$ \\
\end{tabular}} & \multirow[t]{2}{*}{\begin{tabular}{|c|} 
Balance \\
item $^{2}(o d d s$ \\
ratios $)$ \\
\end{tabular}} \\
\hline & $b$ & $\beta$ & & & \\
\hline Sex (female) & $1.382 *$ & -.176 & $2.312 *$ & 1.954* & 2.196* \\
\hline Age: 35 to 44 & -.198 & -.026 & .972 & .951 & .903 \\
\hline Age: 45 and older & -.449 & -.048 & .827 & $.712 * *$ & .777 \\
\hline Med education & .190 & .022 & 1.045 & .905 & $1.424 * *$ \\
\hline High education & .329 & .043 & .934 & 1.002 & $1.550 *$ \\
\hline $\begin{array}{l}2 \text { children }<15 \text { in } \\
\text { household }\end{array}$ & $.783 *$ & .102 & $1.387 *$ & $1.319 *$ & 1.131 \\
\hline $\begin{array}{l}3 \text { or more children }< \\
15 \text { in household }\end{array}$ & $.746 *$ & .070 & $1.678 *$ & $1.571^{*}$ & 1.096 \\
\hline $\begin{array}{l}\text { Child under } 6 \text { in the } \\
\text { household }\end{array}$ & -.007 & -.001 & 1.024 & .876 & 1.060 \\
\hline Work hours: 1 to 29 & -.624 & -.045 & $.602 *$ & .797 & $.363^{*}$ \\
\hline Work hours: 40 to 49 & $.649 *$ & .076 & 1.245 & $1.325 *$ & $1.717 *$ \\
\hline Work hours: 50 to 59 & 1.154* & .100 & $1.822 *$ & $1.807 *$ & $3.892 *$ \\
\hline Work hours: $60+$ & $1.289 *$ & .089 & $2.015 *$ & $1.544 * *$ & $5.139 *$ \\
\hline Works from home & $.641 *$ & .068 & 1.055 & $1.283 * *$ & .879 \\
\hline Works multiple jobs & -.203 & -.013 & .886 & .954 & .707 \\
\hline Has flexible schedule & \begin{tabular}{|l|}
-.369 \\
\end{tabular} & -.048 & .847 & .844 & $.760 *$ \\
\hline $\begin{array}{l}\text { Works nonstandard } \\
\text { hours }\end{array}$ & .084 & .010 & 1.130 & 1.232 & $1.593 *$ \\
\hline $\begin{array}{l}\text { Partner/spouse's } \\
\text { employed part-time }\end{array}$ & .343 & .045 & .843 & 1.119 & .956 \\
\hline $\begin{array}{l}\text { Partner/spouse's } \\
\text { employed full-time }\end{array}$ & .438 & .037 & 1.082 & 1.220 & 1.078 \\
\hline $\begin{array}{l}\text { Partner/spouse does } \\
\text { less }\end{array}$ & .334 & .042 & 1.129 & $1.298 * *$ & 1.211 \\
\hline $\begin{array}{l}\text { Partner/spouse does } \\
\text { more }\end{array}$ & .122 & .016 & 1.016 & 1.190 & 1.247 \\
\hline$\$ 20,000-\$ 39,000$ & -.055 & -.004 & .745 & .779 & 1.719 \\
\hline$\$ 40,000-\$ 59,000$ & \begin{tabular}{|r|}
-.348 \\
\end{tabular} & -.037 & .581 & .680 & 1.565 \\
\hline$\$ 60,000-\$ 79,000$ & \begin{tabular}{|r|}
-.351 \\
\end{tabular} & -.037 & .645 & .730 & 1.720 \\
\hline$\$ 80,000-\$ 99,000$ & .489 & -.049 & $.459 *$ & .553 & 1.729 \\
\hline$\$ 100,000$ and more & .114 & .014 & .567 & .643 & 1.859 \\
\hline Living in a rural area & .057 & .006 & .983 & .918 & 1.009 \\
\hline Sense of belonging & $.849 *$ & -.104 & $.616^{*}$ & $.774 *$ & $.540 *$ \\
\hline Atlantic provinces & $.558 * *$ & .038 & 1.554* & $1.582 *$ & 1.017 \\
\hline Ontario & .448 & .058 & 1.318 & 1.521* & 1.239 \\
\hline $\begin{array}{l}\text { Saskatchewan and } \\
\text { Manitoba }\end{array}$ & .134 & -.009 & .943 & 1.075 & .890 \\
\hline Alberta & .042 & .003 & 1.015 & 1.290 & .852 \\
\hline British Columbia & .217 & .019 & .918 & 1.310 & 1.295 \\
\hline $\mathrm{N}$ & 2018 & & 2039 & 2036 & 2007 \\
\hline (Pseudo)R $\mathrm{R}^{2}$ & 0. & $84 *$ & $0.0560^{*}$ & $0.046^{*}$ & $0.098^{*}$ \\
\hline
\end{tabular}

b: unstandardized regression coefficient; $\beta$ : standardized regression coefficient $* \mathrm{p}<0.01 * * \mathrm{p}<0.05$ (two-tailed test)

1. Do you feel that you're constantly under stress trying to accomplish more than you can handle?

2. Are you satisfied or dissatisfied with the balance between your job and home life? 
ence higher levels of time-related stress than men. Similarly, women are almost two-and-a-half times (odds ratio (o.r.)=2.3) more likely to be severely time-crunched, almost twice (o.r. $=1.95$ ) as likely as men to have the feeling of being constantly under stress as they try to accomplish more than they can handle, and more than twice (o.r. $=2.19)$ as likely than men to be dissatisfied with the balance between their work and family life, controlling for all other variables.

The existing literature points to the importance of work-related factors in accounting for variations in parental stress levels. Indeed, we found that working long hours has a significant effect on the experience of the work-family conflict across all four models. Controlling for all other variables, a working parent who spends $40-49,50-59$ or more than 60 hours a week in paid employment scores an average of one point ( $\mathrm{b}=.649,1.15$, and 1.29 , respectively) higher on the standardized stress scale than a working parent who spends only 30-39 hours a week in paid employment. Long work hours have a similar effect on feeling timecrunched. A working parent who works more than 50 hours a week is twice as likely to feel time-crunched than someone who works 30-39 hours a week. Similarly, a working parent who spends 50-59 hours a week in paid employment is $80 \%$ more likely than a parent who works 30-39 hours a week to feel constantly under stress trying to accomplish more than they can handle. Working over 60 hours a week increases the probability of experiencing such stress by $50 \%$ compared to working 30-39 hours per week. The effect of the number of work hours is most pronounced for the dissatisfaction that working parents feel in their work and home life balance. Parents who work 50-59 hours a week are almost four times (o.r.=3.89) as likely to feel dissatisfied with their work-family balance, and those working more than 60 hours are more than five times (o.r.=5.1) as likely to be dissatisfied.

The existing literature suggests that the availability of support systems can create a positive buffer for time-related stress. Indeed, a strong sense of belonging reduces time pressure, stress, and dissatisfaction with the balance of work and home life. Working parents with a strong sense of belonging to their local community score an average of one point $(b=-.85)$ lower on the standardized stress scale than those who are weakly linked to the community they live in. Similarly, compared to working parents with strong ties to their community, weakly integrated working parents are $60 \%$ more likely to feel a severe time-crunch, $30 \%$ more likely to feel constantly under stress as they try to accomplish more than they can handle, and 85\% more likely to be dissatisfied with their workfamily balance. 
On the other hand, a number of variables had no significant effect across the different conceptualizations and operationalizations of the work-family conflict. Contrary to previous findings, the number of children living in the household seemed to be more important for working parents' experience of time-related stress and time-crunch than the age of the child(ren), a variable which did not contribute significantly to the explanation of the work-family conflict across models. Furthermore, parents who work multiple jobs are not significantly more stressed, timecrunched, or dissatisfied with their work-family balance than parents who hold only one job. This surprising result might be attributed to the fact that we are already controlling for the number of hours the respondent spends in paid employment. In addition, spousal employment did not have significant effects on an individual's level of stress, time-crunch, or perceptions of family-work balance. Last, neither income nor living in rural areas had any statistically significant effects on the four dependent variables.

The effect of some variables depended on how the work-family conflict was operationalized. For example, the number of children under the age of 15 in the household contributes significantly to explaining the observed variance in working parents' time-related stress. Working parents who have two or three and more children under the age of 15 in the household have consistently higher scores on the stress scale $(b=.783$ and .746, respectively) than working parents who have only one child in the household, controlling for all other independent variables. Similarly, working parents with two children in the household are over one-third (39\%) more likely to feel time-crunched and $32 \%$ more likely to feel constantly under stress while trying to accomplish more than they can handle than those who have only one child. Working parents with three or more children are two-thirds $(68 \%)$ more likely to be time-crunched and more than half $(57 \%)$ as likely to feel constantly under stress than parents who have only one child. Conversely, the number of children living in the household had no significant effect on working parent's dissatisfaction with the balance between their work and home life.

Working from home increased time-related stress and the feeling of being stressed while trying to accomplish more than one can handle; this variable did not have a statistically significant effect on feeling time-crunched or on working parents' dissatisfaction with their workhome life balance. Parents who work from home score an average of .64 points higher on the standardized stress scale than those not working from home and are $28 \%$ more likely to feel constantly stressed as they try to accomplish more than they can handle. Likewise, having schedule flexibility or working nonstandard hours significantly affects working 
parents' dissatisfaction with their work-family balance but has no statistically significant effect on the three other dependent variables.

Finally, we examined the effect of the policy context in which working parents operate, operationalized as the province of residence. Based on previous research, we hypothesized that working parents in Québec should experience less time-related stress because the province implemented a number of policies aiding working parents in reconciling work and family responsibilities. We created a series of dummies, each representing one province, leaving Québec out of the analysis as the reference category. However, with exception of the Atlantic Provinces where working parents showed higher stress levels than working parents in Québec, we could not find statistically significant provincial variations in time-related stress. Working parents in the Atlantic provinces scored an average of .56 points higher on the stress scale than working parents in Québec. In all remaining provinces, working parents' stress levels were not significantly different from those measured in Québec. Similarly, working parents in the Atlantic regions were more than twice (55\%) as likely to feel time crunched than working parents in Québec. Finally, working parents in the Atlantic region and Ontario are more than twice as likely (58\% and $52 \%$, respectively) to feel constantly under stress trying to accomplish more than they can handle than those in Québec.

\section{Discussion and Conclusion}

Our first objective in this paper was to explore the effects of a number of independent variables on different conceptualizations and operationalizations of the work-family conflict found in Canadian literature. We compared regression results using our standardized multi-item stress scale as a dependent variable with results using three other conventionally used dependent variables: the dichotomized version of the time-crunch scale, a single-item stress indicator, and a single-item indicator measuring the dissatisfaction with work-family balance. This study demonstrates two important results: first, the way in which the work-family conflict is operationalized affects the results of the research; and second, certain factors significantly contribute to variations in one model but not in others. Only a few predictors held across the different conceptualizations of the family-work conflict.

The time-crunch scale is frequently used in the literature in Canada, though it became clear from our research that studies employing this variable do not discuss its conceptual adequacy. We could not find in these studies a detailed examination of whether the ten items that they 
included actually measure the same conceptual construct. Nor were we able to find a discussion of why individuals answering "yes" to at least seven of the ten questions are deemed time-crunched. Thus, the question that needed to be asked first was whether the time-crunch scale is a theoretically meaningful construct (Piazza 1980). As Beaujot and Andersen (2007) point out, the time-crunch scale is a somewhat problematic measure because it includes a broad range of questions that are not necessarily coherent in terms of their content. The factor analysis that we carried out showed that at least four of the ten items did not load on the same factor indicating that they measure a conceptually distinct construct and thus should not be included in the time-crunch scale (at least for our subsample of working parents). These results raise doubts that the time-crunch scale adequately measures time scarcity as it relates to working parents' efforts to consolidate work and family responsibilities.

In addition, we compared the regression results of our standardized time-related stress scale to two single-item indicators: one measuring stress arising from trying to accomplish more than one can handle and the other capturing dissatisfaction with the balance between work and home life. Our analysis showed that some factors relevant to time-related stress had no significant effect on working parents' dissatisfaction with their work-family balance and vice versa. Asking respondents how satisfied they are with the balance between their work and home life comes closest to the concept of the work-family conflict. Unfortunately, the construct is measured with only a single dichotomous item. Single-item indicators are problematic; when they are coded on a nominal level of measurement, they lack explanatory power and are insufficiently reliable indicators of the construct being measured, particularly when it is as complex as the work-family conflict. Thus, evidence provided by multiitem indicators is often more persuasive than that based on a single-item indicator (Piazza 1980).

Grzywacz and Carlson (2007) argue that recent theoretical and conceptual developments of work-family balance do not reflect the vast academic and popular interest in the issues. We agree with this assessment but also point to the lack of suitable data available to empirically test theoretically derived conceptualizations. In their examination of three US data sets, each measuring the work-family conflict on different scales, Bellavia and Frone (2005) found that research results varied greatly depending on how the work-family conflict was conceptualized. Thus, while theoretical development is certainly important, the empirical verification of theoretical concepts falls short if suitable data sets are difficult to come by. It was not until 2006 that Statistics Canada integrated newer theoretical developments in the conceptualization of the work- 
family conflict in the development of its questionnaire (2006 GSS on Family Transition).

Our second objective in this paper was to examine the impact of different predictors on parents' time stress. We found that women, working parents with two or more children living in the household, parents who work long hours, and those working from home had consistently higher levels of stress than other parents. Working parents who feel integrated in their local community, on the other hand, were found to be less stressed than those who feel excluded. While earlier research suggests that stress levels and their effects vary over the life course (see, for example, Fast and Frederick 2004) we could not find a significant relationship between the age of the parent and time-related stress (after controlling for the number of children and the age of the youngest child). In addition, earlier research showed variations in time-crunch depending on spousal involvement in domestic labour (see, for example, Beaujot and Andersen 2007). With respect to childcare, our results show no relationship between the respondent's stress levels and partner/spouse's involvement in that domain. However, the lack of verifiable effect might be attributable to our crude classification (partner/spouse does more, less, or the same) based on the ratio of time the respondent and his or her partner/spouse spent on childcare.

Our third objective was to examine the possible impact of policy contexts on parents' time stress. Following previous research, we used province of residence as a proxy for different policy contexts in Canada (see, for example, Strandh and Nordenmark 2006). We expected working parents in Québec to show lower levels of time-related stress because the province introduced a number of family-friendly policies over the past decades aiding working families to reconcile work and family responsibilities. However, our results suggest that, with the exception of the Atlantic Provinces and Ontario, working parents in Québec were no less stressed or time-crunched than those living in other provinces. A number of possible reasons might explain the lack of statistically significant differences.

First, just as the concept of the work-family conflict is insufficiently defined, the notion of family-friendly policies lacks theoretical and empirical clarification. Furthermore, the conceptualization, measurement, and interpretation of policies across social contexts remains complex (Woods 2006). Second, it is difficult to assess the effects of family policies on specific outcomes such as working parents' ability to reconcile work and family responsibilities. Individuals and their families are embedded in multifaceted contexts and the interaction between individuals, their families, and various contextual factors is complex and difficult to 
conceptualize (Gornick and Meyers 2003). This difficulty is well illustrated by Strandh and Nordenmark's (2006) analysis of the work-family conflict across varying European policy contexts. They found that in some countries with extensive batteries of family-friendly policies, families continue to experience considerably more conflict between the work and family domain than families in other European countries with less expansive family policies. The authors attribute the high levels of the work-family conflict in those countries to the high labour force participation of women, which leads to higher conflict levels than in countries with lower levels of female labour force participation (for similar results comparing Finland and Australia, see Bittman 1999).

Québec's female labour force participation has historically been consistently lower than in the remaining provinces and women who did work tended to spend fewer hours in paid employment than other working women across Canada. However, since 1997, women with small children in Québec have been entering the labour force at a greater rate than mothers in the other provinces (Lefebvre 2004). Taking into consideration results presented by Strandh and Nordenmark (2006) it seems plausible that Québec's working women are still adapting to the fairly recent entry into the labour market resulting in greater conflict between work and family responsibilities. Furthermore, a number of contextual factors might contribute to stress levels of Québec's working parents which neutralize the possible positive effects of family friendly policies. For example, Québec's relative weak economy, resulting in high levels of unemployment and job insecurity, as well as financial insecurity might strain many individuals and their families (Roy and Bernier 2007). This might explain why parental stress levels in Québec do not significantly differ from those in other provinces that have similar economic conditions but a limited number of family friendly policies.

In addition to contextual factors, one has to take into account other mitigating factors that might offset notable effects of such policies on working parents' ability to combine work and family responsibilities. First, there is an important difference between the introduction of policies and their subsequent implementation (McLaughlin 1987). One specific focus of Québec's family policies is the provision of affordable childcare. However, the provision of subsidized childcare and the increase in the labour market participation of women have led to a dramatic rise in the demand for childcare, which currently cannot be met by existing childcare facilities. As a result, many parents still find it difficult to find childcare (Lefebvre 2004). In addition, Lefebvre (2004) points to a number of other problems including the fact that existing childcare 
facilities cannot accommodate parents who work nonstandard hours, and high quality childcare arrangements are still difficult to find.

Finally, the existence of family-friendly policies at one level, such as the provincial level, albeit important, is by no means sufficient (Jacobs and Gerson 2004). Political guidelines established at the national and provincial level, workplace policies supportive of working families, as well as the ability of individuals to capitalize on existing family-friendly provisions have to go hand in hand (Bellavia and Frone 2005). Individuals have to be knowledgeable about, and appreciative of, policies provided at the provincial and organization level (Roy and Bernier 2007). At the same time, there is evidence that organizational and workplace cultures often curtail policy developments on the provincial and federal level by being generally unsupportive of working parents beyond their legally established rights (Duxbury et al. 2003). Thus, accomplishing work-life balance is a complex issue that requires the interaction and cooperation of agents at the federal, provincial, organizational, as well as the individual level.

In conclusion, the results of the analyses presented in this paper suggest that more research is needed to further develop both theoretical and conceptual frameworks. In addition, to empirically test theoretical and conceptual constructs and examine parents' efforts to combine paid and unpaid work, adequate instruments must be developed. Qualitative methods could shed light on the challenges families encounter in combining paid and unpaid employment, as well as the strategies they employ to cope with the stress arising from competing demands emerging in the public and the private sphere. Furthermore, qualitative methods could explore in detail how families perceive family policies and in what ways policies assist working parents to combine paid and unpaid employment. Finally, as we have demonstrated in this paper, better measurements are needed to adequately capture work-family conflict quantitatively. Qualitative methods could aid in the development of more accurate instruments to measure the degree of working parents' perceived conflict between work and family spheres. Future research in the area of the work-family conflict depends not only on the refinement of theoretical concepts but also on the availability of more suitable data sets to test the hypotheses developed in this paper.

\section{REFERENCES}

Beaujot, Roderic and Robert Andersen. 2007. Time-crunch: Impact of time spent in paid and unpaid work, and its division in families. Canadian Journal of Sociology 32:295-315. 
Bellavia, Gina M. and Michael R. Frone. 2005. Work-family conflict. Pp. 113147 in J. Barling, E.K. Kelloway, and M.R. Frone, eds., Handbook of Work Stress. Thousand Oaks, CA: Sage.

Benoît-Paul, Hébert and Alex Grey. 2006. Time-related stress: Incidence and risk factors. Horizons 8(3):14-23.

Bittman, Michael. 1999. Parenthood without penalty: Time use and public policy in Australia and Finland. Feminist Economics 5(3):27-42.

Bourdais, Céline Le, Nicole Marcil-Gratton, and Danièle Bélanger. 1994. Quebec's pro-active approach to family policy: "Thinking and acting family." Pp. 103-115 in M. Baker, ed., Canada's Changing Families: Challenges to Public Policy. Ottawa: The Vanier Institute of the Family.

Cheal, David, Frances Woolley, and Meg Luxton. 1998. How Families Cope and Why Policy Makers Need to Know. Ottawa: Canadian Policy Research Networks.

Cohen, Sheldon and Thomas Ashby Wills. 1985. Stress, social support, and the buffering hypothesis. Psychological Bulletin 98:310-357.

Cook, Cynthia and J. Doug Willms. 2002. Balancing work and family life. Pp. 183-197 in J.D. Willms, ed., Vulnerable Children. Edmonton: University of Alberta Press.

Cooke-Reynolds, Melissa and Nancy Zukewich. 2004. The feminization of work. Canadian Social Trends 72:24-29.

Doucet, Andrea. 1995. Gender equality and gender difference in household work and parenting. Women's Studies International Forum 18:271-284. 2000. 'There's a huge gulf between me as a male carer and women': Gender, domestic responsibility, and the community as an institutional arena. Community, Work and Family 3:163-184.

Duxbury, Linda, Chris Higgins, and Karen L. Johnson. 1999. An Examination of the Implications and Costs of Work-life Conflict in Canada. Ottawa: Health Canada.

Duxbury, Linda and Christopher Higgins. 1994. Families in the economy. Pp. 29-40 in M. Baker, ed., Canada's Changing Families: Challenges to Public Policy. Ottawa: The Vanier Institute of the Family.

Duxbury, Linda, Christopher Higgins, and Donna Coghill. 2003. Voices of Canadians: Seeking Work-life Balance. Quebec: Human Resources Development Center.

Edwards, Jeffrey R. and Nancy P. Rothbard. 2005. Work and family stress and well-being: Person-environment fit within and between the work and family domains. Pp. 211-242 in E.E. Kossek, and S.J. Lambert, eds., Work and Life Integration: Organizational, Cultural, and Individual Perspectives. Mahwah, NJ: Lawrence Erlbaum. 
Fast, Janet E. and Judith A. Frederick. 2004. The Time of Our Lives: Juggling Work and Leisure Over the Life Cycle (Catalogue No. 89-584-MIE). Ottawa: Statistics Canada.

Frederick, Judith A. and Janet E. Fast. 2001. Enjoying work: An effective strategy in the struggle to juggle? Canadian Social Trends 61(Summer):8-11.

Friede, Alyssa and Ann Marie Ryan. 2005. The importance of the individual: How self-evaluations influence the work-family interface. Pp. 193-209 in E.E. Kossek, and S.J. Lambert, eds., Work and Life Integration: Organizational, Cultural, and Individual Perspectives. Mahwah, NJ: Lawrence Erlbaum.

Gauthier, Anne H. 2007. The impact of family policies on fertility in industrialized countries: A review of the literature. Population Research Policy Review 26:323-346.

Gauthier, Anne H., Timothy M. Smeeding, and Frank F. Furstenberg. 2004. Are parents investing less time in children? Trends in selected industrialized countries. Population and Development Review 30:647-672.

Girard, Philip. 1994. Why Canada has no family policy: Lessons from France and Italy. Osgoode Hall Law Journal 32:579-611.

Glass, Jennifer L. and Sarah Beth Estes. 1997. The family responsive workplace. Annual Review of Sociology 23:289-313.

Gornick, Janet C. and Marcia K. Meyers. 2003. Families That Work: Policies for Reconciling Parenthood and Employment. New York: Russell Sage Foundation.

Granato, Jim, Ronald Inglehart, and David Leblang. 1996. Cultural values, stable democracy, and economic development: A reply. American Journal of Political Science 40:680-696.

Greenhaus, Jeffrey H. and Nicholas J. Beutell. 1985. Sources of conflict between work and family roles. The Academy of Management Review 10:76-88.

Grzywacz, Joseph G. and Dawn S. Carlson. 2007. Conceptualizing work family balance: Implications for practice and research. Advances in Developing Human Resources 9:455-471.

Hays, Sharon. 1996. The Cultural Contradictions of Motherhood. New Haven: Yale University Press.

Hobfoll, Stevan E. and Charles D. Spielberger. 2003. Family stress: Integrating theory and measurement. Pp. 142-157 in P. Boss, and C. Mulligan, eds., Family Stress: Classic and Contemporary Readings. Thousand Oaks, CA: Sage.

Hofferth, Sandra L., April A. Brayfield, Sharon Gennis Deich, and Pamela A. Holcomb. 1991. National Child Care Survey, 1990. Washington, DC: The Urban Institute. 
Jacobs, Jerry A. and Kathleen Gerson. 2001. Overworked individuals or overworked families: Explaining trends in work, leisure, and family time. Work and Occupations 28:40-63.

2004. The Time Divide: Work, Family, and Gender Inequality. Cambridge, MA: Harvard University Press.

Jenson, Jane and Sherry Thompson. 1999. Comparative Family Policy: Six Provincial Stories. Ottawa: Canadian Policy Research Networks.

Kossek, Ellen Ernst and Susan J. Lambert. 2005. "Work-family scholarship": Voice and context. Pp. 3-17 in E.E. Kossek, and S.J. Lambert, eds., Work and Life Integration: Organizational, Cultural, and Individual Perspectives. Mahwah, NJ: Lawrence Erlbaum.

Lapierre-Adamcyk, Evelyne, Nicole Marcil-Gratton, and Céline Le Bourdais. 2006. A balancing act: Parents' work arrangements and family time. Pp. 49-75 in K. McQuillan, and Z.R. Ravanera, eds., Canada's Changing Families - Implications for Individuals and Society. Toronto: University of Toronto Press.

Lefebvre, Pierre. 2004. Quebec's innovative early childhood education and care policy and its weaknesses. Policy Options 25(March):52-57.

Luffman, Jacqueline. 2006. The core-age labour force. Perspectives on Labour and Income 7(9):5-11.

MacDermid, Shelley M. 2005. (Re)considering conflict between work and family. Pp. 19-40 in E.E. Kossek, and S.J. Lambert, eds., Work and Life Integration: Organizational, Cultural, and Individual Perspectives. Mahwah, NJ: Lawrence Erlbaum.

MacDonald, Martha, Shelley Phipps, and Lynn Lethbridge. 2005. Taking its toll: The influence of paid and unpaid work on women's well-being. Feminist Economics 11(1):63-94.

McLaughlin, Milbrey Wallin. 1987. Learning from experience: Lessons from policy implementation. Educational Evaluation and Policy Analysis 9:171-178.

O'Hara, Kathy. 1998. Comparative Family Policy: Eight Countries'Stories. Ottawa: Canadian Policy Research Network.

Organization for Economic Cooperation and Development (OECD). 2005. Babies and Bosses - Reconciling Work and Family Life - Canada, Finland, Sweden and the United Kingdom. vol. 4. Paris: OECD Publishing.

Park, Jungwee. 2007. Work stress and job performance. Perspectives on Labour and Income 8(12):5-17.

Piazza, Thomas. 1980. The analysis of attitude items. The American Journal of Sociology 86:584-603.

Presser, Harriet B. 2004. Working in a 24/7 economy: Challenges for American families. Industrial \& Labor Relations Review 57:625-628. 
Ranson, Gillian. 1999. Paid work, family work and the discourse of the 'full-time mother.' Journal of the Association for Research on Mothering 1:57-66.

Ravanera, Zenaida R. and Kevin McQuillan. 2006. Introduction. Pp. 3-11 in K. McQuillan, and Z.R. Ravanera, eds., Canada's Changing Families Implications for Individuals and Society. Toronto: University of Toronto Press.

Roy, Laurent and Jean Bernier. 2007. Family Policy, Social Trends and Fertility in Québec: Experimenting with the Nordic Model? (Catalogue No. A-5101 (2007-01)). Québec: Ministère de la Famille, des Aînés et de la Condition Féminine.

Saltzstein, Alan L., Yuang Tin, and Grace Hall Saltzstein. 2001. Work-family balance and job satisfaction: The impact of family-friendly policies on attitudes of federal government employees. Public Administration Review 61:452-467.

Statistics Canada. 2005. Births: The Daily, July 12, 2005. Ottawa: Statistics Canada.

2006. Women in Canada: A Gender-based Statistical Report (Catalogue No. 89-503-XIE). Ottawa: Statistics Canada. 2008. Labour Highlight Tables, 2006 Census (Catalogue No. 97-559XWE2006002). Ottawa: Statistics Canada.

Strandh, Mattias and Mikael Nordenmark. 2006. The interference of paid work with household demands in different social policy contexts: Perceived work-household conflict in Sweden, the UK, the Netherlands, Hungary, and the Czech Republic. British Journal of Sociology 57:597-617.

Walker, Alexis J. 1985. Reconceptualizing family stress. Journal of Marriage and the Family 47:827-837.

Williams, Cara. 2008. Work-life balance of shift workers. Perspectives on Labour and Income 9(8):5-16.

Woods, Dorian R. 2006. Focusing on Care: Family Policy and Problems of Analysis (WiP Working Paper Series, Paper Nr. 30.). Tübingen: Institute of Political Science, University of Tübingen.

Zukewich, Nancy. 2003. Work, Parenthood and the Experience of Time Scarcity (Catalogue No. 89-584-MIE2003001). Ottawa: Statistics Canada.

Zuzanek, Jiri. 2000. The Effects of Time Use and Time Pressure on Child-parent Relationships. Waterloo: Otium Publications.

Anne H. Gauthier is the Canada Research Chair in Comparative Family Policy at the University of Calgary. She obtained her doctorate in sociology from the University of Oxford and has since held faculty positions in England, the United States, and Canada. Her research interests include family policy, parenting, fertility, cross-national research, and children's well-being. gauthier@ucalgary.ca

Annette Tézli is a PhD student in Sociology at the University of Calgary. Her 
dissertation research focuses on the lived experience of homeless families in Calgary's booming economy. Other research interests include: social inequality, poverty, modern welfare states, critical theory, critical research strategies, and qualitative research methods.

atezli@ucalgary.ca 